\title{
A Model of Native American Worker Job Satisfaction
}

\author{
Alise Dabdoub \\ University of Oklahoma \\ Stephanie Cross \\ University of Oklahoma \\ Lori Anderson Snyder \\ University of Oklahoma
}

This study tested a model of Native American worker job satisfaction. A similar model was tested on Indigenous New Zealand workers (Haar \& Brougham, 2013). This research attempts to examine if those findings extended to Native American workers. The current study proposed that cultural and family related factors uniquely contribute to Native American worker job satisfaction, more so than factors that are proposed to influence job satisfaction in the majority culture. Results revealed similarities between the model of Indigenous New Zealand worker job satisfaction with organizational support for family, diversity related fairness, work family conflict, all being significant predictors of job satisfaction. Additionally, this study tested if meaningfulness of work, a value purported to be important in many traditional Native American cultures, would contribute to job satisfaction. Results revealed that meaningfulness of work did significantly contribute to job satisfaction for Native American workers. Thus, this study provides some initial evidence for understanding differences in job satisfaction models that may apply for Native American workers.

Keywords: native American workers, job satisfaction, meaningfulness of work, workplace diversity

\section{A MODEL OF NATIVE AMERICAN WORKER JOB SATISFACTION}

Job satisfaction is a highly researched topic within the industrial organizational psychology and management literatures (Brown \& Peterson, 1993; Loher, Noe, Moeller \& Fitzgerald, 1985; Wilkin, 2013). Job satisfaction has been defined as an individual's sentiments regarding the important aspects of their work (Vrrom, 1964). There have been a number of models tested regarding jobs satisfaction which have found outcomes including increased job performance, organizational commitment, organizational citizenship behaviors, life satisfaction and lower absenteeism and intent to quit (Judge \& Watanabe, 1993; Seashore \& Tobor, 1975; Sheraz, Wajid, Sajid, Qureshi \& Rizwan, 2014).

While researchers have investigated differences in job satisfaction between minority and majority workers, one gap in the literature is the lack of focus on Indigenous cultures. There are a number of specificities related to job satisfaction that are proposed to be more important to Indigenous workers than other workers. For example, work-life balance factors, how much the organization values diversity, and 
cultural awareness toward the Indigenous employee or group have been highlighted as important specifically to those with Indigenous backgrounds (Caron, Asselin, Beaudoin \& Muresanu, 2019). Thus, established models of job satisfaction may not accurately represent Indigenous workers' career values (Brougham \& Haar, 2013; Haar \& Brougham, 2013). It is important to consider that job satisfaction may vary from culture to culture, meaning that models created and tested on the White majority U.S. culture may not fit for workers from Indigenous cultures. By including culturally relevant variables in job satisfaction models, understanding of Indigenous worker sentiments can be increased. This understanding is also important for enacting workplace interventions that are culturally relevant, and therefore, more successful.

Haar and Brougham (2013) extended a pre-established model of career satisfaction to understand the differences found between Maori (Indigenous peoples of New Zealand) employees' career satisfaction when compared to that of New Zealanders with European descent. Their model included workplace cultural wellbeing and collectivism; factors already established as valued to Maori workers in previous research. Workplace cultural wellbeing refers to how Indigenous employees feel that their cultural values and beliefs are accepted at work (Haar \& Brougham, 2013). Their results showed that traditional predictors of career satisfaction (work family conflict, hours worked, tenure at the organization, and organizational support for family) did not contribute much variance in explaining Maori career satisfaction. However, cultural wellbeing and collectivism were significant predictors.

This study seeks to test a model similar to Haar and Brougham's (2013) model on Native American workers in the U.S. The present study focuses on job satisfaction rather than career satisfaction due to the nature of our sample (recent graduates who were early on in their careers). Thus, they are less likely to have established longitudinal perceptions of career satisfaction. In addition, this model included meaningfulness of work as another hypothesized culturally relevant factor.

\section{ORGANIZATIONAL SUPPORT}

Organizational Support is conceptualized as having control over one's working conditions and hours (Harr and Brougham, 2013). Several studies have demonstrated how the ability to control one's own working conditions leads to a number of positive outcomes including higher levels job satisfaction and health outcomes for workers (Allen, 2001; Naqvi, Ishtiaq, Kanwal \& Ali, 2013; Taylor, Bradley, Nguyen, 2003). Furthermore, this relationship may be increasingly important within the context of the United States, as studies have shown that $21 \%$ of U.S. workers are required to work overtime (Golden \& Wiens-Tuers, 2005 ), potentially leading to the U.S. being ranked $30^{\text {th }}$ out of 40 countries assessed for having a low amount of leisure time allotted to workers (Capital, 2020).

Family support is especially important to Indigenous workers, as they are more likely to prioritize family obligations above work (Brougham \& Harr, 2013). In the United States, assimilationist policies such as relocation bussed many Native Americans to large cities to gain employment. Decades later, "urban" Native Americans sometimes travel great distances to visit their family lands to continue their cultural practices. Furthermore, due to assimilationist policies and the loss of political and economic autonomy, Native American workers are more likely to be living in poverty and underemployed (Austin, 2013). This often causes them to work jobs with variable schedules or multiple jobs for less pay which can add an additional layer of family detracting obligations that majority culture works likely do not contend with at the same rate. This leads to our first hypothesis:

Hypothesis 1: Individuals who indicate a low level of organizational support will have lower job satisfaction than individuals who indicate their organizations have higher levels of support.

Organizational diversity related fairness pertains to the perception that one's employer applies policies and rules in a consistent and unbiased manner (Choi \& Rainey, 2014). Studies have shown that perceptions of workplace fairness differ between majority and minority groups such that minority group workers tend to perceive the workplace as less fair than White workers (Britton, 1997; Mor Barak, Cherin \& Berkman, 
1998). This is partly due to various forms of discrimination, which is said to be perpetuated by the similarity-attraction hypothesis (Byrne, 1971) which suggests individuals prefer others who they perceive as similar to themselves, as well as Social Identity Theory (Tajfel \& Turner, 1981) which posits individual's ascribe positive characteristics to those who are in their same group. Since Native American workers make up a small percentage of the workforce, it would be fair to assume they likely face an increased amount of discrimination and biased treatment. Discrimination and unfair policy application have shown to be detrimental for job satisfaction in African American, Asian American, and Latino/a workers (Madera, King, Hebl, 2012; Mor Barak et al., 1998). However, no studies have examined this relationship specifically for Native American workers. Considering this, hypothesis 2 is proposed:

Hypothesis 2: Individuals who indicate their organization has higher levels of diversity related fairness, will have higher job satisfaction than those rated their organization as being less fair.

\section{WORK FAMILY CONFLICT}

Spillover models of work life balance suggest that work can influence one's personal life and one's personal life can affect one's work (Guest, 2002). Indigenous peoples tend to be more family oriented (Prindeville \& Gomez, 1999) than the majority culture in which they are situated, hence, work interfering with family may be exceptionally detrimental to their overall job satisfaction. However, due to the familyoriented nature of many Native Americans, one may posit they are less likely to view their family as a source of interference with their work. Lack of work family conflict has been shown to increase job satisfaction in a number of groups including Maori workers (Grandey, Cordeiro \& Crouter, 2005; Haar, Russo, Suñe \& Ollier-Malaterre, 2014), however since Native American workers may not view their family as a source of interruption, family interfering with work may not affect job satisfaction. Thus, hypotheses 3 and 4 are proposed:

Hypothesis 3: There will be no significant relationship between family interfering with work and job satisfaction.

Hypothesis 4: There will be a negative relationship between work interfering with family and job satisfaction such that, lower levels of work-family conflict will coincide with higher levels of jobs satisfaction.

\section{CULTURAL WELLBEING AND COLLECTIVISM}

Cultural wellbeing captures the ways in which an individual feels that their cultural values and beliefs are respected (or not) in their workplace (Haar \& Brougham, 2013). For many Indigenous peoples, culture is a significant component of their experiences and identities. Recognizing this, Harr and Brougham (2013) created a measure that reflected Maori peoples' attitudes about how they view their own cultural wellbeing in the workplace. Similarly, Native American peoples' traditional cultural and ceremonial practices are central to their identity and health (Portman \& Garrett, 2005; Johnson, Swartz, \& Martin 1995). Research has demonstrated that having to suppress one's identity in a work context leads to lower job satisfaction (Madera et al., 2012). Therefore, hypothesis 5 is proposed:

Hypothesis 5: Those high in cultural well-being will have higher job satisfaction than those with lower cultural well-being.

Indigenous cultures tend to be more collectivistic, which puts Indigenous workers at odds with dominant cultural values (Haar \& Staniland, 2016; Redpath \& Nielsen, 1997). Native American peoples share similar collectivistic values, including the prioritization of family and community, consensus-seeking, and humility (James, Wolf, Lovato, \& Byers, 1994). Workplace collectivism refers to a system where 
employees are more concerned with group objectives, harmony, relationships, customs and traditions, rather than individual goals (Caron et al., 2019). Creating a collectivistic workplace has been shown to improve mental health for Maori employees (Brougham \& Haar, 2013) which is related to job satisfaction (Elovainio, Kivimäki, Steen \& Kalliomäki-Levanto, 2000). However, cultural wellbeing maybe more beneficial to some than others. Due to the focus of cultural wellbeing on the individual workers rather than the needs of the entire workplace, collectivism may serve as a moderating factor determining how much the lack of cultural wellbeing affects one's job satisfaction (Haar \& Brougham, 2013). Hence, hypotheses 6 and 7 are proposed:

Hypothesis 6: There will be a significant positive relationship between collectivism and job satisfaction.

Hypothesis 7: Collectivism will moderate the relationship between cultural wellbeing and job satisfaction.

\section{MEANINGFULNESS OF WORK}

Meaningfulness of work can be conceptualized as the belief that one's work or work objectives, as judged in comparison with one's personal standards, have value (May, Gilson \& Harter, 2004). Meaningfulness of work has been shown to be an important predictor of positive job outcomes at the individual level (Hackman \& Oldham, 1980). However, meaningfulness of work can impact Indigenous peoples at the community level. Within the United States, the historical and ongoing colonization of Native Americans has resulted in a number of disparities when compared to the dominant group and other minority groups, including poverty, chronic illnesses, and educational attainment. Thus, due to the community and family-oriented nature of many Native American peoples, they often seek out employment that is beneficial to their communities (Caron et al., 2019; Guillory, 2008). Hence, it is posited that meaningful work is a value held as important to Native American workers, and thus, would be likely related to their level of job satisfaction. Therefore, hypothesis 8 is proposed:

Hypothesis 8: Those who rate the meaningfulness of their work highly will have higher jobs satisfaction than those who rate their work as less meaningful.

\section{MEASURES}

Job satisfaction was measured using the 36-item job satisfaction survey (Spector, 1994). This measure used a 6-point scale which ranged from strongly disagree to strongly agree. A sample items is "My job is enjoyable". This measure demonstrated strong reliability $(\alpha=.90)$.

Organizational support was measured using the 14 item Allen (2001) organizational support for family scale. This measure used a 5-point Likert scale which ranged from strongly disagree to strongly agree scale. Moreover, alpha reliability indicated a high degree of reliability $(\alpha=.80)$. A sample item was "Attending to personal needs, such as taking time off for sick children is frowned upon." This scale is negatively oriented, thus will be referred to as "Lack of Organizational Support" in the analyses section.

Organizational diversity related fairness was measured using the 6-item Mor Barak et al. (1998) scale. This measure used a 5-point Likert scale which ranged from strongly disagree to strongly agree. This measure demonstrated good reliability $(\alpha=.80)$. An example item is "Managers here have a track record of hiring and promoting employees objectively, regardless of their race, sex, religion, or age."

Work-family conflict was measured using the Carlson, Kacmar, and Williams (2000) scale, containing 18 items. This measure used a 5-point Likert scale which ranged from strongly disagree to strongly agree. This measure contained two subscales; work interference with family ("My work keeps me from my family activities more than I would like;" and family interfering with work ("The problem-solving behaviors that work for me at home don't seem to be as useful at work.") both of which had strong reliabilities ( $\alpha=.92$ and 91 respectively). 
Workplace cultural wellbeing was measured using a 4-item scale created by Haar and Brougham (2013). This measure used a 5-point Likert scale which ranged from strongly disagree to strongly agree. The items were modified for Native American workers. A sample item is "I feel satisfied with my organizations' understanding of my tribal culture." This scale demonstrated good reliability $(\alpha=.89)$.

Collectivism was measured using the 6-item created by Clugston, Howell, and Dorfman (2000). This measure used a 5-point Likert scale which ranged from strongly disagree to strongly agree. An example item from this measure is "Group welfare is more important than individual rewards." This scale demonstrated adequate reliability $(\alpha=.78)$.

Meaningfulness of work was measured using a scale created by May et al. (2004). This measure contained 6-items on a 5-point Likert scale which ranged from strongly disagree to strongly agree. A sample item is "The work I do at my job is very important to me." This scale demonstrated strong reliability $(\alpha=$ $.97)$.

Human capital factors included participants' job, tenure, and hours worked. To assess where participants work, "Where are you currently employed?" was asked. Tenure was assessed by asking, "How long have you worked at this job." Hours worked was assessed by asking "On average, how many hours a week do you work."

Socio-Demographic factors included participant age, gender, and marital status. These factors were assessed using a single item indicator for each including "what is your gender" and "are you currently married?" Age was collected from institutional records.

\section{PARTICIPANTS}

Participants included 232 Native American workers who participated in an online survey in Fall 2019 ( $n=160)$ or Spring $2020(n=72)$. There were 96 male and 136 female participants. Most participants were not married $(n=164,71 \%)$, while $68(29 \%)$ participants were married. Participants' average age was 29. Their average job tenure was 3 years and average hours worked per week was 39 hours. All but 30 of the participants listed their current jobs. Of the jobs listed, 60 were in the corporate business sector, 39 were in STEM fields, 34 were in education, 25 were in customer service, 22 were in the health care industry, 11 were in the arts, and 10 were in the political or legal sector. Participants indicated which tribal nation(s) they were enrolled in where the majority of participants indicating they were members of the Cherokee Nation $(\mathrm{N}=66,28 \%)$, Choctaw Nation $(\mathrm{N}=51,22 \%)$, Chickasaw Nation $(\mathrm{N}=26,11 \%)$, Muscogee Creek Nation $(\mathrm{N}=26,11 \%)$, Osage Nation $(\mathrm{N}=10,4 \%)$, Potawatomi Nation $(\mathrm{N}=9,4 \%)$, Comanche Nation $(\mathrm{N}$ $=6,3 \%)$, Seminole Nation $(\mathrm{N}=5,2 \%)$, Shawnee Nation $(\mathrm{N}=3,1 \%)$, Cheyenne, Kiowa, Navajo and Osage Nations each had 2 participants indicating they were enrolled, finally, Arapaho, Apache, Athabaskan, Chippewa, Delaware, Iowa, Lakota, Oneida, Otoe Missouria, Pawnee, Peoria, Pueblo of Jemez, Santa Clara Pueblo, Seneca-Cayuga, and Quapaw Nations all had one enrolled member, with 11 participants declining to answer.

\section{PROCEDURE}

Participants were part of an ongoing longitudinal survey that began when they were enrolled as undergraduate students at a Southwestern University. This survey was administered during both spring and fall semesters while students were enrolled as undergraduates. This survey continually re-recruited the same participants in an effort to track them throughout their undergraduate and post graduate careers. Upon graduation, participants were contacted annually via email to participate in a post-graduation form of the initial survey. This survey took about 30 minutes to complete and asked questions regarding their post graduate experiences including their career. Participants were compensated for their time with a gift card. 


\section{RESULTS}

Data were analyzed using $\mathrm{R}$ studio and the psych package. Descriptive statistics and correlations amongst all study variables were ran (see Table 1). There were several significant correlations amongst study variables, notably all variables were significantly correlated with job satisfaction except collectivism (see Table 2). In addition, no other study variables were significantly correlated with collectivism.

TABLE 1

DESCRIPTIVE STATISTICS AND CORRELATIONS AMONG STUDY VARIABLES

\begin{tabular}{|c|c|c|c|c|c|c|c|c|c|c|}
\hline & $n$ & $M$ & $S D$ & 1 & 2 & 3 & 4 & 5 & 6 & 7 \\
\hline 1. Job Satisfaction & 232 & 4.21 & .82 & & & & & & & \\
\hline $\begin{array}{l}\text { 2. Lack of Organizational } \\
\text { Support }\end{array}$ & 232 & 2.44 & .60 & $-.45^{*}$ & & & & & & \\
\hline $\begin{array}{l}\text { 3. Organizational Diversity } \\
\text { Related Fairness }\end{array}$ & 232 & 3.86 & .91 & $.47 *$ & $-.20 *$ & & & & & \\
\hline $\begin{array}{l}\text { 4. Family Interfering with } \\
\text { Work }\end{array}$ & 232 & 1.88 & .82 & $-.29 *$ & $.26^{*}$ & $-.19^{*}$ & & & & \\
\hline $\begin{array}{l}\text { 5. Work Interfering with } \\
\text { Family }\end{array}$ & 232 & 2.52 & 1.0 & $-.50 *$ & $.39 *$ & $-.26^{*}$ & $.60 *$ & & & \\
\hline $\begin{array}{l}\text { 6. Workplace Cultural } \\
\text { Wellbeing }\end{array}$ & 232 & 3.47 & .95 & $.29 *$ & $-.16^{* *}$ & $.24 *$ & -.06 & $-.17^{*}$ & & \\
\hline 7. Collectivism & 232 & 3.30 & .69 & .08 & .04 & -.06 & .06 & .08 & .04 & \\
\hline 8. Meaningfulness of Work & 232 & 4.09 & 1.0 & $.47 *$ & $-.26^{*}$ & $.21 *$ & $-.17 * *$ & $-.22 *$ & $.32 *$ & $.11 * * *$ \\
\hline
\end{tabular}

Note. $*<.01, * *<.05, * * *$ marginally significant $\mathrm{p}<.07$

A regression analysis was conducted to test the overall model for Native American workers' job satisfaction (see Figure 1). The regression analysis accounted for a total of $54 \%$ of the variance explained in job satisfaction $\left(R^{2}=.54\right)$. Results of the regression revealed several significant findings. Confirming hypothesis 1 , there was a significant negative relationship between organizational support and job satisfaction $(\beta=-.28, p<.001)$. Hypothesis 2 was supported due to a significant positive relationship between organizational diversity related fairness and job satisfaction $(\beta=.25, p<.001)$. Hypothesis 3 was supported as there was no significant relationship between family interfering with work and job satisfaction $(\beta=.04, p=.53)$. Hypothesis 4 was also supported as evidenced by a significant negative relationship between work interfering with family and job satisfaction $(\beta=-.26, p<.001)$. Hypothesis 5 was not supported as there was no significant relationship between workplace cultural wellbeing and job satisfaction $(\beta=-.14, p=.44)$. Neither hypothesis 6 nor 7 were supported as there was no significant relationship between collectivism and job satisfaction $(\beta=-.07, p=.72)$ nor a moderation effect between collectivism, workplace cultural wellbeing, and job satisfaction $(\beta=.06, p=.29)$. There was a significant relationship between meaningfulness of work and job satisfaction $(\beta=-.28, p<.001)$, providing support for hypothesis 8 . Finally, none of the covariate measures (hours worked, marital status, gender, or age) were significantly related to job satisfaction (see Table 2 ) except tenure which showed a significant negative relationship with job satisfaction as tenure increase $(\beta=-.05, p<.001)$. 
TABLE 2

RESULTS OF THE PATH ANALYSIS FOR JOB SATISFACTION FOR INDIGENOUS PEOPLES

\begin{tabular}{llll}
\hline & $\beta$ & $p$ \\
\hline 1. Lack of Organizational Support & -.28 & $<.001$ \\
2. Organizational Diversity Related Fairness & .25 & $<.001$ \\
3. Family Interfering with Work & .04 & .53 \\
4. Work Interfering with Family & -.26 & $<.001$ \\
5. Workplace Cultural Wellbeing & -.14 & .44 \\
6. Collectivism & -.07 & .72 \\
7. Meaningfulness of Work & .23 & $<.001$ \\
8. Collectivism X Workplace Cultural Wellbeing & .06 & .29 \\
9. Job Tenure &.-05 & $<.05$ \\
10. Average Hours Worked per Week & .01 & .26 \\
11. Marital Status & -.01 & .90 \\
12. Age & -.01 & .44 \\
13. Gender & -.01 & .96 \\
\hline
\end{tabular}

Note. Total $\mathrm{R} \mathrm{sq}=.54$

FIGURE 1

PATH MODEL OF JOB SATISFACTION FOR INDIGENOUS PEOPLES

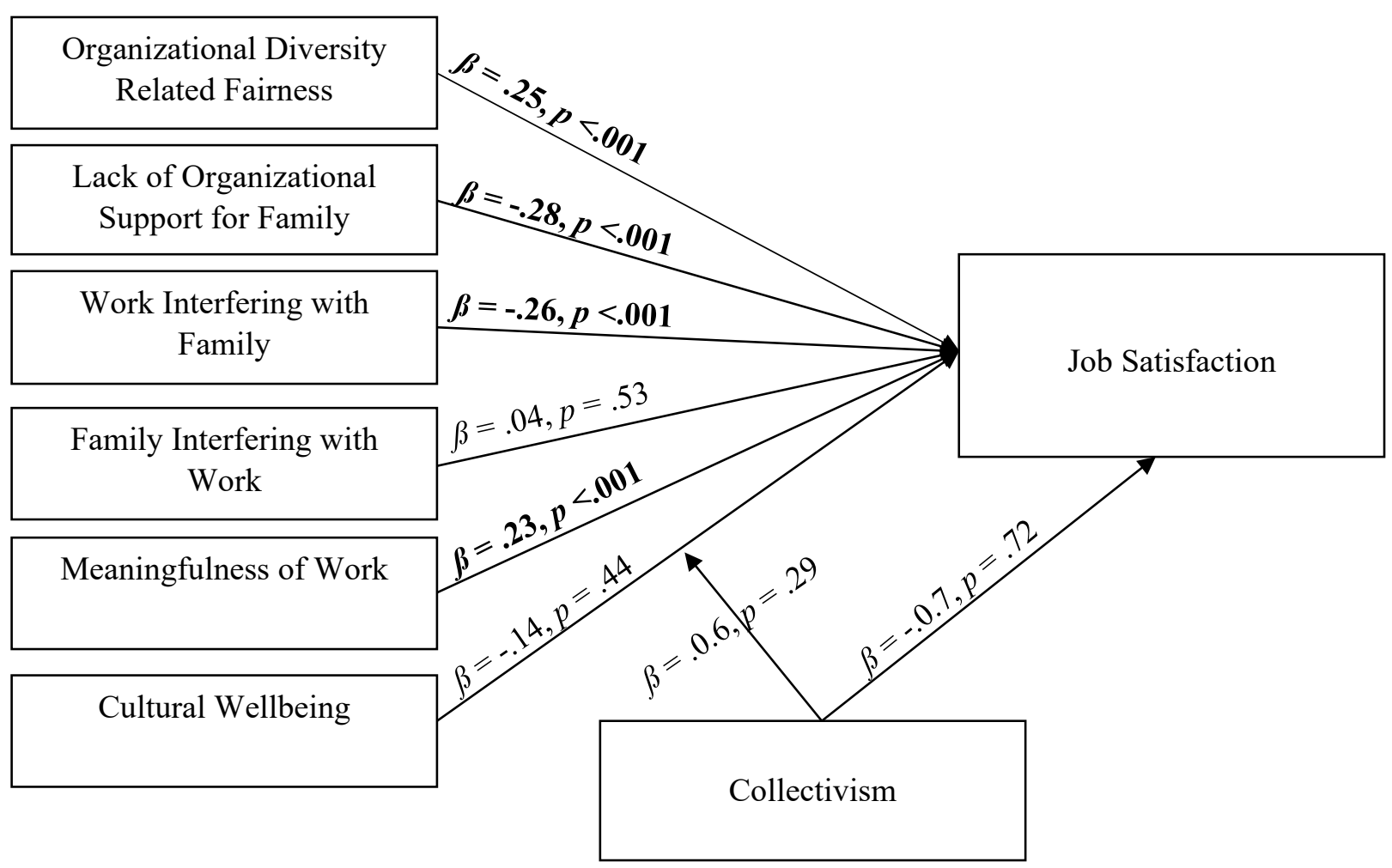

Note. Bolded parameters indicate statistical significance. 


\section{DISCUSSION}

This study attempted to test a model of job satisfaction similar to that of Haar and Brougham's (2013) model of career satisfaction on Native American workers. Results of this study determined that several factors were influential in Native American workers' overall level of job satisfaction. Results for hypothesis one indicated that Native American workers who felt their organization supported their need to devote time to their families outside of work had higher levels of job satisfaction than those who reported their employers were not as concerned with this balance. This result differed from Haar and Brougham (2013) who reported a non-significant relationship between organizational support for family and job satisfaction. This finding could potentially be explained by research indicating that workers in New Zealand rank higher on overall well-being, have more leisure time, and work less hours than workers in the United States (Capital, 2020). Hence, the Maori workers may be less susceptible to their workplaces infringing on their personal time than Native American workers in the United States.

Hypothesis two was supported, demonstrating that Native American workers who perceived their organization as being fair in regard to diversity reported higher job satisfaction. This finding is in line with previous research, which showed that fairness and diversity climate is predictive of job satisfaction for nonmajority workers (Findler, Wind \& Barak, 2007). Therefore, if Native American workers feel like their identity is not a hindrance in their ability to succeed in the workplace, it is likely they will have higher levels or motivation and commitment to their organization (Dubinsky \& Levy, 1989).

Hypothesis three was supported, finding no significant relationship between family interfering with work and job satisfaction. This finding is consistent with literature that proposes that Native American workers are family oriented and would not be likely to perceive family as interfering with work (Prindeville \& Gomez, 1999). Furthermore, analyses indicated a negative relationship between work interfering with family and job satisfaction, supporting hypothesis four. This finding is consistent with Haar and Brougham's (2013) model which found lack of work-family conflict to be a significant predictor of job satisfaction. Thus, when Native American workers perceive that their job is interfering with their family, they become less satisfied with their organization which could lead to higher levels of absenteeism and/or turnover (Boyar, Maertz \& Pearson, 2005; Haar, 2004).

Hypothesis five purported that workplace cultural wellbeing would predict job satisfaction, yet in contrast with the findings of Haar and Brougham (2013), our data did not support this relationship. This could be due to Haar and Brougham (2013) looking at one major tribal nation-Maori-which, while diverse, does not contain the multitudes of identities that "Native American" does in the United States. There are over 567 federally recognized tribal nations within the United States, thus, while we substituted "tribal" for "Maori" in the cultural wellbeing measure, the meaning of this term may vary for citizens of different tribal nations.

In opposition to Haar and Brougham's (2013) findings there was no significant relationship between collectivism and job satisfaction, nor did collectivism show a moderating relationship between workplace cultural wellbeing and job satisfaction (hypotheses six and seven). Both Haar and Brougham (2013) and Caron et al. (2019) explain that Indigenous peoples tend to be more collectivistic than individualistic, however much of this data is derived from Indigenous groups outside of the United States. It might be possible that, given the smaller population of Native Americans within the United States (1\%; Norris, Vines, \& Hoeffel, 2012), they may feel pressure to conform to the dominant individualistic culture, especially when working at jobs that are not related to any tribal nation.

There was a significant relationship between meaningfulness of work, and job satisfaction, thus supporting hypothesis eight. This finding is consistent with literature which has stated that Native American peoples tend to be community-oriented and seek jobs in which they can give back to their communities in a meaningful way (Guillory, 2008). This is also illustrated by the fact that a sizeable number of participants occupied jobs considered more altruistic, such as education and health care. Hence, this finding indicates that when considering job satisfaction for Native American workers, making the meaningfulness of the job itself salient should prove effective. Moreover, organizations may consider workplace programs that 
enhance meaningfulness of work such as encouraging volunteering in the community during work hours and fostering relationships with charities.

Finally, in line with Haar and Brougham's (2013) model, covariate measures including hours worked, age, gender, and marital status did not show any significant relationship with job satisfaction. However, interestingly, tenure was negatively related to job satisfaction such that longer tenured employees were less satisfied. This could be due to the nature of our sample which consisted of recent graduates who may be starting off in their careers and thus may have not found a job that satisfies their long-term goals yet.

Overall, this study found several similarities and differences to the Haar and Brougham (2013) model when examining Native American workers. We found that, for Native American workers, organizational fairness and meaningfulness of work had positive relationships with job satisfaction such that if works felt like their organization was fair regardless of a person's minority group status or their work was personally meaningful, they were more likely to have high levels of job satisfaction. In addition, lack of organizational support, work interfering with family, and job tenure were found to be negatively related to job satisfaction. This indicates that the longer someone worked at their company or if the company caused them to be overworked or was not supportive of their personal lives and time, they were less likely to have high levels of job satisfaction. Interestingly, cultural wellbeing and collectivism were not predictive of job satisfaction for Native American workers as it was for Maori workers. Hence, although both groups are indigenous workers placed in a majority European based society, there are important distinctions between how the two groups perceive job satisfaction. Thus, one must apply caution conducting interventions or applying theories developed on non-US indigenous populations to Native American workers.

Practical implications from this study include the consideration of cultural factors for Native American workers. Culture-based ideologies of both prioritizing family as well as doing meaningful work predicted job satisfaction for Native American workers. Thus, workplace interventions aimed at Native American workers should ensure that workers are able to work in a balanced fashion that does not disrupt their family life. Additionally, making the meaningfulness of one's role salient for Native American workers may have benefits to their levels of job satisfaction.

Being that $54 \%$ of the variance in job satisfaction was explained by this model, there are many more factors which may be tested in attempt to gain a comprehensive understating of job satisfaction for Native American workers. Future studies should consider investigating the extent to which additional such as workplace culture, psychological safety, and discrimination factors may impact Native American worker job satisfaction. It might also be useful to fully replicate Haar and Brougham's (2013) study by including career rather than job satisfaction with a sample with a more diverse range of employee tenure.

\section{REFERENCES}

Allen, T. (2001). Family-supportive work environments: The role of organizational perceptions. Journal of Vocational Behavior, 58(3), 414-435.

Austin, A. (2013). Native Americans and Jobs: The Challenge and the Promise. Retrieved October 27, 2020, from https://www.epi.org/publication/bp370-native-americans-jobs/

Boyar, S.L., Maertz, C.P., Jr., \& Pearson, A.W. (2005). The effects of work-family conflict and familywork conflict on nonattendance behaviors. Journal of Business Research, 58(7), 919-925.

Britton, D.M. (1997). Perceptions of the work environment among correctional officers: Do race and sex matter? Criminology, 35(1), 85-106.

Brougham, D., \& Haar, J. (2013). The Effects of Supervisor Work-Family Support on Indigenous Employees: A Study of Job and Health Outcomes. Labour, Employment and Work in New Zealand.

Byrne, D. (1971). The attraction paradigm. New York, NY: Academic Press.

Capital, N. (2020). How's Life? 2020 Measuring Well-being. OECD.

Carlson, D.S., Kacmar, K.M., \& Williams, L.J. (2000). Construction and initial validation of a multidimensional measure of work-family conflict. Journal of Vocational Behavior, 56(2), 249276. 
Caron, J., Asselin, H., Beaudoin, J.M., \& Muresanu, D. (2019). Promoting perceived insider status of indigenous employees. Cross Cultural \& Strategic Management.

Choi, S., \& Rainey, H.G. (2014). Organizational fairness and diversity management in public organizations: Does fairness matter in managing diversity? Review of Public Personnel Administration, 34(4), 307-331.

Clugston, M., Howell, J.P., \& Dorfman, P.W. (2000). Does cultural socialization predict multiple bases and foci of commitment? Journal of Management, 26(1), 5-30.

Dubinsky, A.J., \& Levy, M. (1989). Influence of Organizational Fairness on Work Outcomes of Re. Journal of Retailing, 65(2), 221.

Elovainio, M., Kivimäki, M., Steen, N., \& Kalliomäki-Levanto, T. (2000). Organizational and individual factors affecting mental health and job satisfaction: A multilevel analysis of job control and personality. Journal of Occupational Health Psychology, 5(2), 269.

Findler, L., Wind, L.H., \& Barak, M.E.M. (2007). The challenge of workforce management in a global society: Modeling the relationship between diversity, inclusion, organizational culture, and employee well-being, job satisfaction and organizational commitment. Administration in Social Work, 31(3), 63-94.

Golden, L., \& Wiens-Tuers, B. (2005). Mandatory overtime work in the United States: Who, where, and what? Labor Studies Journal, 30(1), 1-25.

Grandey, A., Cordeiro, B., \& Crouter, A. (2005). A longitudinal and multi-source test of the work-family conflict and job satisfaction relationship. Journal of Occupational and Organizational Psychology, 78(3), 305-323.

Guest, D.E. (2002). Perspectives on the study of work-life balance. Social Science Information, 41(2), $255-279$.

Guillory, J.P. (2008). Diverse pathways of "giving back" to tribal community: Perceptions of Native American college graduates. Washington State University.

Haar, J., \& Staniland, N. (2016). The Influence of Psychological Resilience on the Career Satisfaction of Māori Employees: Exploring the Moderating Effects of Collectivism. New Zealand Journal of Human Resources Management, 16.

Haar, J.M. (2004). Work-family conflict and turnover intention: Exploring the moderation effects. New Zealand Journal of Psychology, 33(1), 35.

Haar, J.M., \& Brougham, D.M. (2013). An indigenous model of career satisfaction- Exploring the role of workplace cultural wellbeing. Social Indicators Research, 110(3), 873-890.

Haar, J.M., Russo, M., Suñe, A., \& Ollier-Malaterre, A. (2014). Outcomes of work-life balance on job satisfaction, life satisfaction and mental health: A study across seven cultures. Journal of Vocational Behavior, 85(3), 361-373.

Hackman, J.R., \& Oldham, G.R. (1980). Work redesign. Reading, MA: Addison-Wesley.

James, K., Wolf, W., Lovato, C., \& Byers, S. (1994). Barriers to workplace advancement experienced by Native Americans.

Johnson, M.J., Swartz, J.L., \& Martin, W.E. (1995). Applications of psychological theories for career development with Native Americans. Career Development and Vocational Behavior of Racial and Ethnic Minorities, pp. 103-136.

Judge, T.A., \& Watanabe, S. (1993). Another look at the job satisfaction-life satisfaction relationship. Journal of Applied Psychology, 78(6), 939.

Madera, J.M., King, E.B., \& Hebl, M.R. (2012). Bringing social identity to work: The influence of manifestation and suppression on perceived discrimination, job satisfaction, and turnover intentions. Cultural Diversity and Ethnic Minority Psychology, 18(2), 165.

May, D.R., Gilson, R.L., \& Harter, L.M. (2004). The psychological conditions of meaningfulness, safety and availability and the engagement of the human spirit at work. Journal of Occupational and Organizational Psychology, 77(1), 11-37. 
Mor Barak, M.E., Cherin, D.A., \& Berkman, S. (1998). Organizational and personal dimensions in diversity climate: Ethnic and gender differences in employee perceptions. The Journal of Applied Behavioral Science, 34(1), 82-104.

Naqvi, S.R., Ishtiaq, M., Kanwal, N., \& Ali, M. (2013). Impact of job autonomy on organizational commitment and job satisfaction: The moderating role of organizational culture in fast food sector of Pakistan. International Journal of Business and Management, 8(17), 92.

Norris, T., Vines, P.L., \& Hoeffel, E.M. (2012). The American Indian and Alaska Native Population: 2010. 2010 Census Briefs. Retrieved from https:/www.census.gov/history/pdf/c2010br-10.pdf

Portman, T.A.A., \& Garrett, M.T. (2005). Beloved Women: Nurturing the Sacred Fire of Leadership From an American Indian Perspective. Journal of Counseling \& Development, pp. 284-291.

Prindeville, D.M., \& Gomez, T.B. (1999). American Indian women leaders, public policy, and the importance of gender and ethnic identity. Women \& Politics, 20(2), 17-32.

Redpath, L., \& Nielsen, M.O. (1997). A comparison of native culture, non-native culture and new management ideology. Canadian Journal of Administrative Sciences/Revue Canadienne des Sciences de l'Administration, 14(3), 327-339.

Seashore, S.E., \& Tobor, T.D. (1975). Job satisfaction and their correlation. American Behavioral Scientist, 18, 333-368. http://dx.doi.org/10.1177/000276427501800303

Sheraz, A., Wajid, M., Sajid, M., Qureshi, W.H., \& Rizwan, M. (2014). Antecedents of Job Stress and its impact on employee's Job Satisfaction and Turnover Intentions. International Journal of Learning \& Development, 4(2), 204-226.

Spector, P.E. (1994). Job satisfaction survey.

Tajfel, H., \& Turner, J.C. (1985). The social identity theory of intergroup behavior. In S. Worchel \& W.G. Austin (Eds.), The psychology of intergroup relation (pp. 7-24). Chicago, IL: Nelson-Hall. Taylor, J., Bradley, S., \& Nguyen, A.N. (2003). Job autonomy and job satisfaction: New evidence. Vroom, V.H. (1964). Work and motivation. New York John Wiley. 